\title{
Introduced grey squirrels subvert supplementary feeding of suburban wild birds
}

Article

Accepted Version

Creative Commons: Attribution-Noncommercial-No Derivative Works 4.0

Hanmer, H. J., Thomas, R. L. and Fellowes, M. D. E. (2018) Introduced grey squirrels subvert supplementary feeding of suburban wild birds. Landscape and Urban Planning, 177. pp. 10-18. ISSN 0169-2046 doi:

https://doi.org/10.1016/j.landurbplan.2018.04.004 Available at https://centaur.reading.ac.uk/76790/

It is advisable to refer to the publisher's version if you intend to cite from the work. See Guidance on citing.

To link to this article DOI: http://dx.doi.org/10.1016/j.landurbplan.2018.04.004

Publisher: Elsevier

All outputs in CentAUR are protected by Intellectual Property Rights law, including copyright law. Copyright and IPR is retained by the creators or other copyright holders. Terms and conditions for use of this material are defined in the End User Agreement.

www.reading.ac.uk/centaur

\section{CentAUR}


Central Archive at the University of Reading

Reading's research outputs online 
5

6

7

8

9

10

\section{Been caught stealing: Introduced Grey Squirrels subvert supplementary feeding of suburban wild birds}

Hugh J. Hanmer ${ }^{1}$, Rebecca L. Thomas ${ }^{1,2}$ \& Mark D. E. Fellowes ${ }^{1 *}$

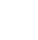

${ }^{1}$ People and Wildlife Research Group, School of Biological Sciences, University of Reading, Whiteknights, Reading, Berkshire, RG6 6AS, UK

${ }^{2}$ School of Biological Sciences, Royal Holloway University of London, Egham, Surrey, TW20 OEX, UK

"Corresponding author: Mark Fellowes

Tel.: +44 (0) 1183787064

Email address: m.fellowes@reading.ac.uk

Hugh Hanmer: $\underline{\text { h.j.hanmer@pgr.reading.ac.uk }}$

Rebecca Thomas: rebecca.thomas@reading.ac.uk

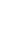

Short running title: Grey Squirrels and supplementary bird feeders

Key words: Garden birds, Grey Squirrel, human-wildlife interactions, supplementary feeding, urban ecology 
Providing food for wild birds is perhaps the most widespread intentional interaction between people and wildlife. In the UK, almost half of households feed wild birds, often as peanuts and seed supplied in hanging feeders. Such food is also taken by the introduced, invasive Grey Squirrel Sciurus carolinensis. Little is known of how Grey Squirrels utilise this resource and how they affect feeder use by wild birds. To assess this we recorded the numbers and time spent by animals visiting experimental feeding stations in suburban gardens, and also asked if exclusionary guards (to prevent Grey Squirrel access), food type (peanut, mixed seed), habitat and weather conditions influenced visits. Using automated cameras, we recorded 24825 bird and 8577 Grey Squirrel visits. On average $>44 \%$ of the time feeders were utilised, they were being visited by Grey Squirrels. Grey Squirrel presence prevented birds from feeding at the same time (>99.99\%). Feeders where Grey Squirrels were dominant were less likely to be visited by birds, even in their absence. Guards reduced Grey Squirrel use to a minimum on seed feeders, and by approximately half on peanut feeders. Squirrels, food type, guard status, habitat and rainfall all influenced bird activity and timing of feeder visits. Our work suggests that Grey Squirrels reduce the availability of supplementary food to wild birds, while gaining large volumes of food resources with corresponding benefits. Given the ubiquity of supplementary feeding, it is likely that this is an important resource for urban Grey Squirrels; feeder 47 guards mitigate this effect. 
63

64

65

66

67

68

69

70

Globally, over half of people live in urban areas (UN, 2011), rising to over $80 \%$ of national populations in countries such as the UK and USA (UNPFA, 2007). Urban areas are extremely altered, novel ecosystems, where native species face challenges and opportunities unlike any other. For birds urban ecosystems can be a place to exploit for urban adapters (Kark et al., 2007; Evans et al., 2011), in part due to the very high volumes of supplementary food (Davies et al., 2009; Orros and Fellowes, 2015) provided by human residents. Conversely, urban ecosystems can be challenging, as urban areas have exceptionally high densities of predators, such as the domestic cat (Felis catus) (Thomas et al., 2012), and introduced competitor/predator species such as the Eastern Grey Squirrel (Sciurus carolinensis; hereafter the Grey Squirrel) (Bonnington et al., 2014b, c). Understanding the interplay between such factors and bird abundance and diversity must be an important link in our efforts to build opportunities for bird conservation in our towns and cities.

Urban areas generally, and in particular the surrounding suburban areas, hold large populations of many bird species (Bland et al., 2004; Cannon et al., 2005), and for some species suburbia provides a refuge for declining populations (e.g. the UK Red listed Song Thrush (Turdus philomelos); Gregory and Baillie 1998). Garden bird feeding is perhaps the most important way for people to engage with wildlife in many parts of the world (Cox and Gaston, 2016). Some $48 \%$ of households in Britain (Davies et al., 2009) and 53 million households in the USA feed wild birds (US Fish and Wildlife Service, 2014), providing an enormous and highly localized additional food resource (Orros and Fellowes, 2015).

Suburban feeding stations typically provide supplementary food for seed-eating and omnivorous passerines (Lepczyk et al., 2004; Cannon et al., 2005; Chamberlain et al., 2005). In the UK, the most common supplementary food types provided (i.e. non-table scraps) are peanuts and mixed seed, each typically provided in specialist feeders (Orros and Fellowes, 2015). Positive associations between supplementary feeding, breeding population size and reproductive success have been documented (Fuller et al., 2008; Robb et al., 2008), although this is not always so (Harrison et al., 2010; Plummer et al., 2013). Indeed, recent work in both the UK and North America suggests that supplementary feeding during the breeding season may increase local nest predation (Hanmer et al., 2017a; Malpass et al., 2017). Some species may also benefit more than others due to the suitability of food provided and relative competitive ability and adaptability of some species (Evans et al., 2009; Evans et al., 2011). Therefore, supplementary feeding may be directly and indirectly affecting the structure of urban bird communities (Galbraith et al., 2015).

Despite the enormous influence of supplementary food on the ecology of urban birds, we have little understanding of how this resource may be utilised by non-target species, and the consequential effects on the species the resource is intended to support. In the UK, the most visible mammal at supplementary feeding stations is the Grey Squirrel. Grey Squirrels were deliberately introduced into Great Britain on several occasions between 1876 and 1929 and elsewhere in Europe during the $20^{\text {th }}$ century (Bertolino et al., 2008). In Britain, the Grey Squirrel is common in urban areas (Baker and Harris, 2007; Bonnington et al., 2014c), and is spreading rapidly from introductions in other parts of Europe (Bertolino et al., 2008). Grey Squirrels are considered to be a significant conservation threat, particularly to the native Red Squirrel (Sciurus vulgaris) (Bertolino et al., 2014). Grey Squirrels carry disease (squirrelpox, Bruemmer et al. 2010; Borrelia burgdorferi, the agent of Lyme disease, Millins et al., 2015, Millins et al., 2016), and cause economic losses in forestry (Mayle and Broome, 2013). In the context of this work, evidence suggests that urban Grey Squirrel population size and density is associated with the provision of supplementary food in gardens (Bowers and Breland, 1996; Parker and Nilon, 2008) and there is some evidence that they can competitively exclude birds at 
supplementary feeders (Hewson et al., 2004; Bonnington et al., 2014a). Bonnington et al. (2014a) used taxidermied Grey Squirrels on feeders, and showed that resource use by birds was reduced by $98 \%$ in the presence of a mounted animal. However, we have no quantitative data on how the presence of live Grey Squirrels affects feeder usage by garden birds, nor how much of the food provided is taken by the squirrels. This is crucial, as the Grey Squirrel is both a competitor for supplementary resources and a nest predator, and so may locally directly and indirectly affect the breeding success of some native bird populations (Newson et al., 2010; Bonnington et al., 2014b; Hanmer et al., 2017a).

Furthermore, a highly conservative estimate suggests that enough supplementary food is provided in the UK (Orros and Fellowes, 2015) to support a Grey Squirrel population around four times the estimated 2.5 million individuals found in the country (Battersby, 2005). What is not understood is how much supplementary food is actually taken by Grey Squirrels. It is thought that Grey Squirrels typically spend considerable periods of time using supplementary feeders (Pratt, 1987), but no published study to our knowledge has attempted to quantify this experimentally using live wild animals over a prolonged period or considered how this affects feeder use by different urban bird species.

Nevertheless, while data are lacking, both purchasers and manufacturers of feeding stations have recognised that Grey Squirrels may be consuming food intended for birds, so specialised feeders and feeder guards are produced to counter this. Typically, standard feeders are surrounded by guards to prevent access by squirrels and other large species such as corvids and invasive parakeets (Antonov and Atanasova, 2003; Sorace and Gustin, 2009). Such guards should decrease the food taken by Grey Squirrels and thus their negative impact on supplementary feeder usage by target birds (Bonnington et al., 2014a; Hanmer et al., 2017a). Furthermore, if the presence of Grey Squirrels reduces resource intake rates by birds (Bonnington et al., 2014a), we may expect to see a behavioural response to their presence. We speculate that excluded species may respond to high levels of Grey Squirrel presence by altering the timing of their visits to established supplementary feeding stations, thus extending foraging opportunities or utilising alternative food sources.

We have little understanding of how providing food may be unintentionally affecting the very species people wish to support due to the use of feeding stations by non-target species, such the invasive Grey Squirrel. Here, we report the results of a manipulative field experiment in suburban gardens using live birds and Grey Squirrels for the first time. The objectives were to investigate a) how Grey Squirrel presence affected the rate and timing of feeder use by garden birds, and whether this interaction was altered $b$ ) by the type of food resource provided (peanuts or mixed seed) or $c$ ) the presence of a feeder guard. Furthermore, we examine how these overall patterns of feeder utilisation were influenced by d) local (urban) habitat or e) weather conditions.

\section{Methods}

\section{Study Area}

This study was conducted in the suburbs of the large urban district centred on Reading, South East England. Greater Reading covers approximately $72 \mathrm{~km}^{2}$ and has a population of $\sim 290000$ people (Office for National Statistics 2013). The eastern suburbs of Lower Earley and Woodley where fieldwork was carried out have human populations of 32,000 and 35,470 individuals respectively.

\section{Individual Site Selection}


To represent typical suburban residential areas in the southern UK, twenty study areas of predominately detached/semi-detached houses at least $500 \mathrm{~m}$ apart and $>100 \mathrm{~m}$ away from any patches of natural or public urban green space (such as parks and playing fields) were selected. One volunteer participant who already fed birds regularly using bird feeders was recruited in each of the 20 areas. Areas selected were broadly similar in terms of local habitat availability, with housing densities of $\sim 10$ households/ha and 30-50 \% constructed surfaces, with garden sizes of 100-200 m².

Experimental work was carried out between 4 September and 30 November 2014. A paired peanut and two port seed feeder (CJ Wildlife small defender feeders, Shrewsbury, UK) on the same feeder stand was placed in each of the 20 volunteer back gardens. Food supplied was the Hi-Energy No Mess Seed Mix (c.550 calories per 100g) and Premium Whole Peanuts (c.560 calories per $100 \mathrm{~g}$ ) from CJ Wildlife (Shrewsbury UK). Feeding stations were placed ca. $2 \mathrm{~m}$ clear from garden boundaries and vegetation cover, and the feeders were within $0.5 \mathrm{~m}$ of each other at least 10 days before the start of data recording to allow animals to discover them. Ten gardens received a wire cage guarded (using individual CJ Wildlife small feeder guardian cages) pair of feeders to exclude Grey Squirrels and other large animals (locally these are primarily Eurasian Magpies (Pica pica), Western Jackdaws (Corvus monedula) and Great Spotted Woodpeckers (Dendrocopus major)) and ten received a pair of identical but unguarded feeders. No other feeders or artificial food sources were present in the study gardens during this period. Feeders may have been present in adjacent gardens, but all were at least $20 \mathrm{~m}$ distant and were believed to be similar across the sites. Feeder visitors were recorded using an infra-red motion triggered camera trap (Ltl Acorn 5310; Ltl Acorn Inc, Wisconsin, USA) which could record visits to both feeders at the same time. The camera was set to record 10 second video clips with a one minute gap between each recording to maximise memory and battery life. The lag time between triggering movement and the camera recording was $0.6 \mathrm{~s}$. Feeders were refilled up to twice a week depending on need, to ensure that feeders were never empty.

\section{Video processing}

The presence of all individuals was recorded to species for every video featuring an animal on a feeder. Feeding visits were recorded to feeders rather than to individuals as individual identification was not possible. The time spent on the feeders by every individual videoed animal was recorded to the nearest full second. Visits to each food type (peanut or seed) were recorded separately. Days where part of the data were missing, such as through the temporary loss of a feeder, view obstruction or with gaps where food was clearly missing were not included in the analyses.

\section{Metrological and habitat data}

Meteorological data for each study day was sourced from the metrological station on the University of Reading's Whiteknights campus $\left(51^{\circ} 270 \mathrm{~N}, 0^{\circ} 580 \mathrm{~W}\right)$ on the edge of Lower Earley, positioned within $4.4 \mathrm{~km}$ of all the study gardens. Weather data for amount of rain $(\mathrm{mm})$, proportion of time spent raining, maximum wind speed $(\mathrm{m} / \mathrm{s})$ and minimum and average temperature $\left({ }^{\circ} \mathrm{C}\right)$ was recorded for the 24 hour period beginning $0900 \mathrm{GMT}$ but for simplicity was attributed to the calendar date. Habitat data for the proportion of gardens (mixed surfaces), buildings and trees for a $200 \mathrm{~m}$ buffer around each study garden was calculated in ArcGIS 10 (ESRI 2011) as defined by land use data from the Ordnance Survey Mastermap collection (EDINA, University of Edinburgh) and distance to the closest woodland fragment (defined as a wooded area of over $400 \mathrm{~m}^{2}$ in area) measured. 
All analyses were carried out within the program R version 3.4 (R Core Team, 2017). Species identity, length of time (in seconds) and time of visit was noted for every recorded feeder visit by an animal. Daily total numbers and recorded time on feeders were calculated for each individual feeder and garden for every full recording day. Individual records were pooled to create a summary for the feeder usage for each day, for every individual bird feeder, as well as an overall summary daily for each feeding station.

Collinearity in explanatory weather and habitat variables was assessed using variance inflation factors (VIF) with a threshold of VIF $=3$, above which variables were excluded from analyses (Zuur et al., 2007). This resulted in the removal of the proportion of buildings and trees within $200 \mathrm{~m}$, amount of rain, maximum wind speed, and minimum and average temperature as explanatory variables. This left the proportion of habitat made up of gardens within $200 \mathrm{~m}$, distance to closest woodland patch $(\mathrm{km})$ and the proportion of the day spent raining as factors in further analyses.

To examine effectors on daily visits and time spent on different types of bird feeders by birds and squirrels, Poisson distribution general linear mixed effect models (GLMMs) were performed in $\mathrm{R}$ package Ime4 (version 1.1-12; Bates et al. 2015) with an observation-level random effect added to account for high levels of over-dispersion (Harrison, 2014). Global models were constructed a priori for each individual animal usage variable. Feeding station (i.e. study garden) and observation day were included as random effects to account for repeated measures. Independent factors included in these global GLMMs were whether the feeders were guarded, food type, total proportion of recorded animal visit time made up by Grey Squirrels that day for that feeding station, the proportion of garden habitat within $200 \mathrm{~m}$, the distance in kilometres to the closest patch of woodland and the proportion of the 24 hour period spent raining. To account for the various potential influences of feeder guards and food type on Grey Squirrel and bird feeder usage a threeway interaction between guard presence, food type and proportion time taken by squirrels was included. Separate models were run for both visit and time data with individual models for all birds and individual species of birds as well as the squirrels. For GLMMs considering factors affecting squirrel feeder usage this variable with the proportion of squirrel time on feeder was not included, making a two-way interaction between food type and guard status instead.

Following Grueber et al. (2011) each global model was then standardised prior to model selection and averaging using R package arm (version 1.9-3; Gelman et al. 2009). Relative model fit of all possible models within the relevant global models was then evaluated for each set of candidate models using $\triangle \mathrm{AICC}$ and Akaike weights for global models against a null model (Burnham and Anderson, 2002) using the "dredge" function in R package MuMin (version 1.15.6; Barton, 2016). As multiple models were found within two $\triangle \mathrm{AICC}$ of all AICc selected models, model averaging was used to produce a conditional average model with adjusted standard errors in the R package MuMin (Barton, 2016). For these average models the relative importance of each term (including interactions) was automatically calculated as a sum of the Akaike weights over all of the models in which the term appears (Barton, 2016).

Examination of the data showed that due to variation between gardens in animal visiting rates, it was not possible to directly test if there was also reduction in bird visits in the absence of Grey Squirrels. Therefore we grouped feeders into low ( $\leq 50 \%)$ and high (>50\%) Grey Squirrel use. MannWhitney $\mathrm{U}$ tests were carried out to compare the mean daily number of overall birds visiting and the mean daily total time spent on feeders by birds between feeders with high and low Grey Squirrel use. 
To explore the effect of guarding feeding stations on the timing of the first feeding first in a day Mann-Whitney $U$ tests were carried out within species and for birds overall. To account for changes in day length, time of first visit was converted to hours from sunrise. Spearman's rank correlation was then used to test for any significant correlations between Grey Squirrel feeder usage and bird visit timing. To account for multiple comparisons made between species, $p$ was automatically adjusted to account for the false discovery rate.

\section{$\underline{\text { Results }}$}

A total of 24825 individual bird (of 16 species) and 8577 individual squirrel visits were recorded, totalling 128473 and 77178 recorded seconds respectively across 881 recording days. Accounting for camera errors and other data loses, 19 gardens and 38 bird feeders were each monitored for a mean of 48 days (median $=45$, range $=17-80$ ). Blue Tits (Cyanistes caeruleus), Great Tits (Parus major) and Grey Squirrels combined accounted for the majority of feeder usage across all feeder types (Figure 1).

\section{Determinants of feeder usage}

In addition to bird visits overall, and Grey Squirrel visits, Blue Tit, Coal Tit (Periparus ater), Dunnock (Prunella modularis), Great Tit, Eurasian Nuthatch (Sitta europaea) and European Robin (Erithacus rubecula) produced converging models for recorded visits allowing model averaging to take place. Models using daily time on feeders are included in STable 1 and STable 2.

\section{Food type}

Seed feeders received more overall daily bird visits than peanut feeders (Table 1). All individual bird species examined were also more likely to visit seed feeders (Table 2), though the difference varied with Blue Tits showing little difference compared to the other species and unlike all other bird species they spent more time on peanut feeders (STable 2). In comparison, Grey Squirrels favoured peanut feeders (Table 1).

\section{Guard status}

Unguarded feeders received considerably more overall bird visits than guarded feeders (15663 and 9162 visits respectively) and were associated in the models overall with an increased number of birds visiting feeders (Table 1), and increased numbers of Blue Tit, Dunnock and Robin visits (Table 2). Coal Tit, Great Tit and Nuthatch showed increased visits rates at guarded feeders, although in the case of Great Tit the effect was negligible (Table 2). Guarding did reduce the number of Grey Squirrel visits (Table 1). This suggests that it was an effective exclusionary method against Grey Squirrels, but also some species of birds were discouraged from visiting by the use of feeder guards (Table 1; Table 2).

\section{Feeder usage by Grey Squirrels}

Increased Grey Squirrel usage of feeders was associated with reduced visits by birds overall (Table 1, Figure 2). Similarly, this was associated with a decrease in Blue Tit, Coal Tit, Great Tit and Robin feeder visits (Table 2), indicating an exclusionary effect. However, Grey Squirrel usage was positively associated with Dunnock visits and showed no influence on Nuthatches (Table 3 ) suggesting that Grey Squirrels had no or little direct effect on their use of feeders or that other factors such as food and habitat are more important in driving their use of feeders. 
281 The interactions between Grey Squirrel feeder usage and food type for Blue Tit, Coal Tit and Dunnock were positive, which may reflect an increased preference for seed feeders with increased Grey Squirrel presence (Table 2). Great Tit and Nuthatch showed the opposite pattern (Table 2), which may be a negative response to the increased presence of Grey Squirrels. There were negative interactions between Grey Squirrel feeder usage and guard type with Dunnock and Nuthatch (Table 2), suggesting displacement by Grey Squirrels from unguarded feeders. For Grey Squirrel visits, the interaction between seed feeders and unguarded feeders was also positive (Table 1), suggesting that Grey Squirrels were associated with unguarded rather than guarded seed feeders. Likewise, Robin showed a similar positive significant association with a preference for unguarded seed feeders (Table 2) whereas Dunnock, Great Tit and Nuthatch showed the opposite relationship indicating a preference for unguarded seed feeders over guarded seed feeders (Table 2), although for Dunnock the effect was small. Between food type, guard status and Grey Squirrel usage there was a negative three-way interaction for Dunnock (Table 2) indicating unguarded feeders discourage them, possibly due to the presence of Grey Squirrels. This three-way interaction was positive with Nuthatch, suggesting a preference for seed and guarded feeders regardless of the presence of Grey Squirrels (Table 2).

Habitat

The proportion of gardens within $200 \mathrm{~m}$ was negatively associated with overall bird visits (Table 1), and specifically for Blue Tit, Dunnock, Great Tit, Nuthatch and Robin visits (Table 2) suggesting the increased availability of alternative food sources in the local area leads to a smaller concentration of these species at feeders. Grey Squirrel and Coal Tit were positively associated with garden habitat availability, suggesting they preferred garden habitats (Table 1 and 2). Increased distance from woodland was associated with increased bird visits overall (Table 1) and for species, increased Blue Tit, Great Tit and Nuthatch visits (Table 2). However, increased distance from woodland was associated with reduced Grey Squirrel ( $F=-3.46$; Table 1 ) as well as Coal Tit, Dunnock and Robin visits (Table 2). This suggests that some species are more reliant than others on woodland patches and may suggest that birds moving further away may be seeking to avoid competition by Grey Squirrels, with the pattern found in birds overall driven by Blue and Great Tit as the commonest bird species recorded.

\section{Rainfall}

Rain was a minor negative predictor of overall bird visits (Table 1) and specifically for Blue Tits, Great Tit, Nuthatch and Grey Squirrel visits (Table 1 and Table 2) while it had a small positive effect on Robin visits (Table 2), suggesting that while rain could affect feeder usage, this was relatively unimportant compared to the other variables considered.

\section{Influence of Grey Squirrel feeder dominance on bird usage}

317 Grey Squirrels were dominant (present $>50 \%$ of the recorded overall usage time) on five of the 19 318 feeding stations. Significantly fewer birds visited feeders daily on average where Grey Squirrels were dominant, indicating that even when they were absent the numbers of birds using feeders heavily frequented by them was depressed $(W=13, p=0.044)$. Birds also spent significantly less daily time on average on Grey Squirrel dominated feeders $(W=12, p=0.034)$. 
Blue Tits and Robins arrived first to feeders earlier in the day with increasing time present on feeders by Grey Squirrels $\left(r_{s}=-0.09, p=0.036\right.$ and $r_{s}=-0.10, p=0.044$ respectively), while Great Tits, European Greenfinches (Chloris chloris) and House Sparrows (Passer domesticus) arrived later $\left(r_{s}=\right.$ $0.14, p=0.002 ; r_{s}=0.27, p=0.018 ; r_{s}=0.32, p=0.004$; respectively). Birds overall, Grey Squirrel and Blue Tit were found to make their first visit in a day significantly earlier to unguarded feeding stations than guarded whereas Coal Tit, Greenfinch (albeit non-significant), House Sparrow and Long-tailed Tit (Aegithalos caudatus) showed the opposite pattern (Figure 3). Only 147 visits (0.044\% of all visits) by all animal types were recorded before sunrise.

\section{Discussion}

The presence of Grey Squirrels on bird feeders in our study system reduced both absolute numbers and length of time birds spent accessing supplementary food, confirming anecdotal and past indirect experimental evidence (Bonnington et al., 2014a).The presence of a Grey Squirrel effectively excluded all birds from a feeding station, and at our study sites they were present on average for $44.3 \%$ of the recorded total feeding time on unguarded feeding stations during a day. This is a minimum value, as video clips were limited to 10 seconds per minute, and in contrast to Grey Squirrels, most bird species spent much less than this time per visit (Figure 4). Grey Squirrels and most bird species were more often associated with unguarded feeders. More birds were recorded using seed feeders, but Grey Squirrels preferred peanut feeders. Grey Squirrels and most bird species were less likely to use feeders on days with increased rainfall. The response to habitat was mixed with Grey Squirrels and several bird species less likely to use feeders that were further away from woodland patches while the commonest bird species (Blue Tit and Great Tit) were more likely to use them when closer to woodland patches. Intriguingly, increased feeder use by Grey Squirrels was associated with changes in the start of feeding for several bird species, suggesting that they were altering their foraging behaviour in response to these species. Together, we show that Grey Squirrels are dominant at bird feeders, reduce food availability to target bird species, and that visiting birds may alter their patterns of feeder use to compensate for reduced feeding opportunities.

Grey Squirrels effectively prevent small birds from accessing feeders while present, and overall most species studied showed a reduction in numbers using feeders associated with an increase in feeder use by Grey Squirrels. Only 10 cases were recorded ( $<99.99 \%$ of records) of a bird (all either Blue Tit or Great Tit) taking food while a squirrel was present at a feeding station and never when two squirrels were present. Furthermore, the reduction in overall bird activity on feeders dominated by Grey Squirrels in addition to increasing Grey Squirrel usage suggests that not only is the time available for birds to feed reduced, but also that the effect lasts longer than individual squirrel visits to feeders. It is worth speculating on what this means in terms of Grey Squirrel energy consumption at feeding stations. Taking the estimated energy supplied per garden per day for UK from Orros and Fellowes (2015) which was a median of $628 \mathrm{kcal} /$ day and a minimum provisioning of $101 \mathrm{kcal} / \mathrm{day}$ (assuming all food was consumed and ignoring food type differences), and making the highly conservative assumption that all species feed at the same rate, then a median of $278 \mathrm{kcal} / \mathrm{day}$ ( 45 $\mathrm{kcal} /$ day minimum) of food intended for wild birds is being taken by Grey Squirrels at unguarded feeders in this experimental system. While by necessity this is simply an estimate, this suggests that such feeder use alone could support the average daily energy requirements ( $137 \mathrm{kcal} / \mathrm{day})$ of two adult Grey Squirrels (Harris and Yalden, 2008; Orros and Fellowes, 2015). At guarded feeding stations 
Grey Squirrels were largely but not entirely excluded, as they were sometimes able to access food though the top of the guarded bird feeders. This shows that feeder guards are an effective means of reducing the volume of food taken by unintended beneficiaries (Orros and Fellowes, 2015).

Nevertheless, while the use of guards did reduce competition with small birds by Grey Squirrels. In absolute numbers small birds preferentially visited unguarded feeders, suggesting that guards may also discourage them to an extent. Only Dunnock showed a preference for guarded feeders, with all other species showing no preference. This suggests that while garden owners can reduce the volume of food taken by species such as Grey Squirrels, this may come at a cost in terms of reduced use of guarded feeders by small birds. We speculate that this may be a result of the feeder guards presenting a barrier to escape or delaying predator detection (Devereux et al., 2006; Cresswell et al., 2009), increasing the risks associated with using the feeders.

The use of baffles designed to stop Grey Squirrels from being able to access feeders may offer an alternative means of reducing access of squirrels to food, while not restricting or discouraging bird access. However, such feeding equipment will still allow other potential competitors and nest predators such as corvids (Hanmer et al., 2017a) to access food. Feeders which are capable of excluding animal access to food based on weight avoid this problem, but the increased costs involved in purchasing such exclusionary feeders may greatly discourage members of the public from using them, although the greater cost may be offset by the reduced volumes of food taken by larger feeder users with higher energy requirements (Orros and Fellowes, 2015).

We have some evidence that birds may alter their daily first visiting times in response to local rates of feeder use by Grey Squirrels, showing similar patterns to those seen with increased activity of hawks (Roth and Lima, 2007). Blue Tits and Robins arrived to feeders earlier and Great Tits, Greenfinches and House Sparrows arrived later with increasing use of feeders by Grey Squirrels. The two species arriving earlier may be showing a behavioural response where they attempt to feed before the arrival of Grey Squirrels to feeders and so avoid exclusion from the resource by extending their potential feeding time. The three species arriving later may be unable to adapt in this way or are utilising other resources first instead to account for this exclusion. Guarded feeding stations also significantly altered the timing of first visit for several species. Blue Tits and Greenfinches as well as birds overall arrived significantly earlier to feed on unguarded feeders. Conversely, Coal Tits, House Sparrows and Long-tailed Tits arrived earlier on guarded feeders. When feeders are guarded and therefore larger animals excluded, there may therefore be less need to adjust feeding behaviour to avoid exclusion by these larger competitors.

Sites were purposefully selected to be broadly similar in local habitat and garden size. However, local habitat did influence both bird and Grey Squirrel supplementary feeder usage. For Grey Squirrel, birds overall and most bird species examined (with the exception of Coal Tit), an increasing proportion of garden habitat within $200 \mathrm{~m}$ of a feeding station was negatively associated with feeder usage, suggesting that where alternative food sources were available, these were increasingly used. Feeder usage by Grey Squirrels and several bird species declined with increasing distance from nearest woodland patch. These woodland patches are likely to provide resting sites and enemy free space given domestic cat roaming behaviour (Thomas et al., 2014; Hanmer et al., 2017b). This suggests that feeding stations in urban areas further away from woodland patches may be more available to small birds due to fewer Grey Squirrels being present, as suggested by the increased feeder visits by Blue Tit and Great Tit in gardens further away from woodland patches, although bird numbers may still be depressed at supplementary feeding stations in more highly urbanised areas even in the absence of this competition (Chace and Walsh, 2006; Tratalos et al., 2007; Bonnington et al., 2014b). 
The autumn of 2014 was relatively mild with no frosts, snow or extreme weather events recorded during the monitoring period so it was unsurprising that no influence of temperature or wind speed was found on bird visits or length of time on feeders. However, increased rain duration depressed both bird and Grey Squirrel feeding activity to some extent. These results conflict with Cowie and Simons (1991) who found wind but not rain to be related to feeding activity and Zuckerberg et al. (2011) who found precipitation (including snowfall) to be associated with increased winter feeder usage in some North American passerines.

Perhaps it is worth thinking of the relationship between the garden owners who provide supplementary food and the garden birds who feed on that food as a mutualism, where in exchange for food resources, birds provide pleasure and perhaps even health benefits to the many millions of people who feed them (Cox and Gaston, 2015, 2016; Cox et al., 2017). In this context, Grey Squirrels take food from the intended beneficiaries, with the longer term consequence of benefitting Grey Squirrel population growth. However, it should also be noted that many people in the UK have positive attitudes towards Grey Squirrels, purposefully allowing them to benefit from supplementary food (Rotherham and Boardman, 2006). Irrespective of motivation, we suggest that the use of bird supplementary feeding stations by Grey Squirrels leads to both reduced availability of food for garden birds, and potentially increases the rate of local nest predation in the breeding season (Hanmer et al., 2017a). Furthermore, this may contribute to the success of Grey Squirrels as their range expands and further comes into conflict with forestry and Red Squirrel conservation efforts in the UK. People can use guarded feeders as a counter-measure, but at the cost of possibly reducing feeder use by most garden birds. Despite this, we suggest that given the potential direct and indirect consequences of unintentionally providing very large volumes of supplementary food to Grey Squirrels, it would be wise to provide supplementary food in a manner which limits access to this invasive species.

\section{References}

Antonov, A., Atanasova, D., 2003, Small-scale differences in the breeding ecology of urban and rural magpies Pica pica, Ornis Fennica 80(1):21-30.

Baker, P. J., Harris, S., 2007, Urban mammals: What does the future hold? An analysis of the factors affecting patterns of use of residential gardens in Great Britain, Mammal Review 37(4):297315.

Barton, K., 2016, MuMIn: Multi-Model Inference. R package version 1.15.6.

Bates, D., Maechler, M., Bolker, B., Walker, S., 2015, Fitting linear mixed-effects models using Ime4, Journal of Statistical Software 67(1):1-48.

Battersby, J., 2005, UK mammals: Species status and population trends, JNCC/Tracking Mammals Partnership, Peterborough, UK.

Bertolino, S., Lurz, P. W. W., Sanderson, R., Rushton, S. R., 2008, Predicting the spread of the American grey squirrel (Sciurus carolinensis) in Europe: A call for a co-ordinated European approach, Biological Conservation 141(10):2564-2575.

Bertolino, S., di Montezemolo, N. C., Preatoni, D. G., Wauters, L. A., Martinoli, A., 2014, A grey future for Europe: Sciurus carolinensis is replacing native red squirrels in Italy, Biological Invasions 16(1):53-62.

Bland, R. L., Tully, J., Greenwood, J. J. D., 2004, Birds breeding in british gardens: An underestimated population?, Bird Study 51(2):97-106.

Bonnington, C., Gaston, K. J., Evans, K. L., 2014a, Assessing the potential for grey squirrels Sciurus carolinensis to compete with birds at supplementary feeding stations, Ibis 156(1):220-226. 
Bonnington, C., Gaston, K. J., Evans, K. L., 2014b, Relative roles of grey squirrels, supplementary feeding, and habitat in shaping urban bird assemblages, PLOS ONE 9(10):e109397.

Bonnington, C., Gaston, K. J., Evans, K. L., 2014c, Squirrels in suburbia: Influence of urbanisation on the occurrence and distribution of a common exotic mammal, Urban Ecosystems 17(2):533546.

Bowers, M. A., Breland, B., 1996, Foraging of gray squirrels on an urban-rural gradient: Use of the gud to assess anthropogenic impact, Ecological Applications 6(4):1135-1142.

Bruemmer, C. M., Rushton, S. P., Gurnell, J., Lurz, P. W. W., Nettleton, P., Sainsbury, A. W., Duff, J. P., Gilray, J., McInnes, C. J., 2010, Epidemiology of squirrelpox virus in grey squirrels in the UK, Epidemiology and Infection 138(7):941-950.

Burnham, K. P., Anderson, D. R., 2002, Model Selection and Multimodel Inference: A Practical Information-Theoretic Approach, Springer, New York, USA.

Cannon, A. R., Chamberlain, D. E., Toms, M. P., Hatchwell, B. J., Gaston, K. J., 2005, Trends in the use of private gardens by wild birds in Great Britain 1995-2002, Journal of Applied Ecology 42(4):659-671.

Chace, J. F., Walsh, J. J., 2006, Urban effects on native avifauna: A review, Landscape and Urban Planning 74(1):46-69.

Chamberlain, D. E., Vickery, J. A., Glue, D. E., Robinson, R. A., Conway, G. J., Woodburn, R. J. W., Cannon, A. R., 2005, Annual and seasonal trends in the use of garden feeders by birds in winter, Ibis 147(3):563-575.

Cowie, R. J., Simons, J. R., 1991, Factors affecting the use of feeders by garden birds: I. The positioning of feeders with respect to cover and housing, Bird Study 38:145-150.

Cox, D. T. C., Gaston, K. J., 2015, Likeability of garden birds: Importance of species knowledge \& richness in connecting people to nature, PLOS ONE 10(11):e0141505.

Cox, D. T. C., Gaston, K. J., 2016, Urban bird feeding: Connecting people with nature, PLOS ONE 11(7):e0158717.

Cox, D. T. C., Shanahan, D. F., Hudson, H. L., Fuller, R. A., Anderson, K., Hancock, S., Gaston, K. J., 2017, Doses of nearby nature simultaneously associated with multiple health benefits, International Journal of Environmental Research and Public Health 14(2):172.

Cresswell, W., Butler, S., Whittingham, M. J., Quinn, J. L., 2009, Very short delays prior to escape from potential predators may function efficiently as adaptive risk-assessment periods, Behaviour 146(6):795-813.

Davies, Z. G., Fuller, R. A., Loram, A., Irvine, K. N., Sims, V., Gaston, K. J., 2009, A national scale inventory of resource provision for biodiversity within domestic gardens, Biological Conservation 142(4):761-771.

Devereux, C. L., Whittingham, M. J., Fernández-Juricic, E., Vickery, J. A., Krebs, J. R., 2006, Predator detection and avoidance by starlings under differing scenarios of predation risk, Behavioral Ecology 17(2):303-309.

Evans, K. L., Newson, S. E., Gaston, K. J., 2009, Habitat influences on urban avian assemblages, Ibis 151(1):19-39.

Evans, K. L., Chamberlain, D. E., Hatchwell, B. J., Gregory, R. D., Gaston, K. J., 2011, What makes an urban bird?, Global Change Biology 17(1):32-44.

Fuller, R. A., Warren, P. H., Armsworth, P. R., Barbosa, O., Gaston, K. J., 2008, Garden bird feeding predicts the structure of urban avian assemblages, Diversity and Distributions 14(1):131-137.

Galbraith, J. A., Beggs, J. R., Jones, D. N., Stanley, M. C., 2015, Supplementary feeding restructures urban bird communities, Proceedings of the National Academy of Sciences 112(20):E264857.

Gelman, A., Su, Y.-S., Yajima, M., Hill, J., Pittau, M. G., Kerman, J., Zheng, T., Dorie, V., 2009, arm: Data analysis using regression and multilevel/hierarchical models. R package, version 1.9-3.

Gregory, R. D., Baillie, S. R., 1998, Large-scale habitat use of some declining British birds, Journal of Applied Ecology 35(5):785-799. 
Grueber, C. E., Nakagawa, S., Laws, R. J., Jamieson, I. G., 2011, Multimodel inference in ecology and evolution: challenges and solutions, Journal of Evolutionary Biology 24(4):699-711.

Hanmer, H. J., Thomas, R. L., Fellowes, M. D. E., 2017a, Provision of supplementary food for wild birds may increase the risk of local nest predation, Ibis 159(1):158-167.

Hanmer, H. J., Thomas, R. L., Fellowes, M. D. E., 2017b, Urbanisation affects range size of the domestic cat (Felis catus): consequences for conservation, Journal of Urban Ecology 3(1):jux014.

Harris, S., Yalden, D. W. Y., 2008, Mammals of the British Isles: handbook, The Mammal Society, Southampton.

Harrison, T. J. E., Smith, J. A., Martin, G. R., Chamberlain, D. E., Bearhop, S., Robb, G. N., Reynolds, S. J., 2010, Does food supplementation really enhance productivity of breeding birds?, Oecologia 164(2):311-320.

Harrison, X. A., 2014, Using observation-level random effects to model overdispersion in count data in ecology and evolution, PeerJ 2:e616.

Hewson, C. M., Fuller, R. A., Mayle, B. A., Smith, K. W., 2004, Possible impacts of grey squirrels on birds and other wildlife, British Wildlife 15(3):183-191.

Kark, S., Iwaniuk, A., Schalimtzek, A., Banker, E., 2007, Living in the city: Can anyone become an 'urban exploiter'?, Journal of Biogeography 34(4):638-651.

Lepczyk, C. A., Mertig, A. G., Liu, J., 2004, Assessing Landowner Activities Related to Birds Across Rural-to-Urban Landscapes, Environmental Management 33(1):110-125.

Malpass, J. S., Rodewald, A. D., Matthews, S. N., 2017, Species-dependent effects of bird feeders on nest predators and nest survival of urban American robins and northern cardinals, The Condor 119(1):1-16.

Mayle, B. A., Broome, A. C., 2013, Changes in the impact and control of an invasive alien: The grey squirrel (Sciurus carolinensis) in Great Britain, as determined from regional surveys, Pest Management Science 69(3):323-333.

Millins, C., Magierecka, A., Gilbert, L., Edoff, A., Brereton, A., Kilbride, E., 2015, An invasive mammal (grey squirrel, Sciurus carolinensis) commonly hosts diverse and atypical genotypes of the zoonotic pathogen Borrelia burgdorferi sensu lato, Applied and Environmental Microbiology 81(13):4236-4245.

Millins, C., Gilbert, L., Johnson, P., James, M., Kilbride, E., Birtles, R., Biek, R., 2016, Heterogeneity in the abundance and distribution of Ixodes ricinus and Borrelia burgdorferi (sensu lato) in Scotland: implications for risk prediction, Parasites \& Vectors 9(1):595.

Newson, S. E., Leech, D. L., Hewson, C. M., Crick, H. Q. P., Grice, P. V., 2010, Potential impact of grey squirrels Sciurus carolinensis on woodland bird populations in England, Journal of Ornithology 151(1):211-218.

Orros, M. E., Fellowes, M. D. E., 2015, Wild bird feeding in a large UK urban area: Characteristics and estimates of energy input and individuals supported, Acta Ornithologica 50(1):43-58.

Parker, T. S., Nilon, C. H., 2008, Gray squirrel density, habitat suitability, and behavior in urban parks, Urban Ecosystems 11(3):243-255.

Plummer, K. E., Bearhop, S., Leech, D. I., Chamberlain, D. E., Blount, J. D., 2013, Winter food provisioning reduces future breeding performance in a wild bird, Scientific Reports 3:2002.

Pratt, C. R., 1987, Gray squirrels as subjects in independent study, The American Biology Teacher 49(8):434-437.

R Core Team, 2017, R: A language and environment for statistical computing, R Foundation for Statistical Computing, Vienna, Austria.

Robb, G. N., McDonald, R. A., Chamberlain, D. E., Reynolds, S. J., Harrison, T. J. E., Bearhop, S., 2008, Winter feeding of birds increases productivity in the subsequent breeding season, Biology Letters 4(2):220-223.

Roth, T. C., Lima, S. L., 2007, The predatory behavior of wintering Accipiter hawks: Temporal patterns in activity of predators and prey, Oecologia 152(1):169-178. 
Rotherham, I. D., Boardman, S., 2006, Who says the public only love red squirrels, ECOS 27(1):28-35. gradients, Landscape and Urban Planning 90(3-4):111-118. domestic cats (Felis catus) and the acceptability of possible management actions in the UK, PLOS ONE 7(11):e49369.

Thomas, R. L., Baker, P. J., Fellowes, M. D. E., 2014, Ranging characteristics of the domestic cat (Felis catus) in an urban environment, Urban Ecosystems 17(4):911-921.

Tratalos, J., Fuller, R. A., Evans, K. L., Davies, R. G., Newson, S. E., Greenwood, J. J. D., Gaston, K. J., 2007, Bird densities are associated with household densities, Global Change Biology 13(8):1685-1695.

UN, 2011, World population prospects: The 2010 revision, United Nations, Department of Economic and Social Affairs, Population Division, New York.

UNPFA, 2007, The state of World population 2007: Unleashing the potential of urban growth, United Nations Population Fund, New York.

US Fish and Wildlife Service, 2014, 2011 National survey of fishing, hunting, and wildlife-associated recreation, Washington DC.

Zuckerberg, B., Bonter, D. N., Hochachka, W. M., Koenig, W. D., DeGaetano, A. T., Dickinson, J. L., 2011, Climatic constraints on wintering bird distributions are modified by urbanization and weather, Journal of Animal Ecology 80(2):403-413.

583

584

585

586 
Table 1. Standardised average Poisson generalized mixed effect models of effectors on recorded visits on peanut and seed feeders at unguarded and guarded feeding stations for total birds and Grey Squirrels with all models converging within delta 2 AICC of their respective minimal models. Where: Feeding station identity and study day were random effects, Food = food type (peanut set to intercept), Guard = guard status (guarded set to the intercept), Distance $=$ distance to closest woodland patch, Garden\% = the proportion of habitat made up by gardens within $200 \mathrm{~m}$, Rain\% = the proportion of the day spent raining and ' $:$ ' indicates an interaction term between covariates. Both Null models had $\triangle \mathrm{AICC}>50$ and model weights $\leq 0.001$. Relative importance indicates the relative importance of the covariate across the models within $\Delta 2 \mathrm{AICc}$ of the AICc selected model, as a sum of the Akaike weights over all of the models in which the term appears and $\mathrm{N}$ indicates the number of models the covariate featured in.

Table 2. Standardised average Poisson generalized linear mixed effect models for daily recorded visits on peanut and seed feeders at unguarded and guarded feeding stations for all bird species with all models converging within delta 2 AICC of their respective minimal models. All Null and Global models had delta AICcs $>4$ to their respective minimal models. Where: Feeding station identity and study day were random effects, Food = food type (peanut set to intercept), Guard = guard status (Guarded set to intercept), Squirrel\% = daily proportion of total feeder usage by squirrels, Garden $\%=$ proportion of garden within $200 \mathrm{~m}$, Rain\% = Proportion of day spent raining, Distance = distance $(\mathrm{km})$ to closest patch of woodland and ' $:$ ' indicates an interaction term between covariates. Relative importance indicates the relative importance of the covariate across the models selected for averaging, as a sum of the Akaike weights over all of the models in which the term appears and $\mathrm{N}$ indicates the number of models the covariate featured in.

\section{$610 \quad$ Figure legends}

611 Figure 1. Proportion of animal visits and time as metrics of bird feeder usage for the different types

612 over the course of the study. $\mathrm{N}=426$ and 454 total observation days for guarded and unguarded 613 supplementary feeding stations respectively.

614 Figure 2. Effect of Grey Squirrel feeder usage (proportion of total daily time on feeders) on a) total 615 daily visits and $b$ ) total daily time spent on feeding stations (both feeders together). Fitted with a 616 smoothed line of best fit with 95\% confidence intervals based on locally weighted regression for 617 illustrative purposes.

618 Figure 3. Summary of the median ( \pm IQR) time of first visit after sunrise for Grey Squirrels, all birds 619 and all common bird species for guarded and unguarded feeding stations. Mann-Whitney test 620 statistics are between the first visit by that species/grouping in a day to a guarded and unguarded 621 feeding station. For P value significance: $\bullet p=0.1-0.05, * p<0.01, * * p<0.001, * * * p<0.0001$ 622 (adjusted using the false discovery rate).

623 Figure 4. Median ( $\pm \mathrm{IQR}$ ) recorded individual visit time (up to 10 second videos) spent on all different 624 types of bird feeders in the study by species with interquartile ranges. 
630

\begin{tabular}{|l|l|l|l|r|l|l|}
\hline $\begin{array}{l}\text { Tested } \\
\text { Model }\end{array}$ & Variables & Estimate & SE & P & $\begin{array}{l}\text { Relative } \\
\text { Importance }\end{array}$ & N \\
\hline \multirow{5}{*}{ Birds } & Intercept & 1.201 & 0.4416 & 0.0065 & N/A & N/A \\
\cline { 2 - 7 } & Distance & 0.5655 & 0.8891 & 0.5247 & 0.15 & 2 \\
\cline { 2 - 7 } & Food & 0.9682 & 0.055 & $<0.0001$ & 1 & 10 \\
\cline { 2 - 7 } & Food : Squirrel\% & -0.2059 & 0.1344 & 0.1253 & 0.53 & 5 \\
\cline { 2 - 7 } & Garden\% & -1.514 & 0.8553 & 0.0768 & 0.79 & 8 \\
\cline { 2 - 7 } & Guard & -0.5966 & 1.0099 & 0.5547 & 0.14 & 2 \\
\cline { 2 - 7 } & Rain\% & -0.1102 & 0.0592 & 0.0625 & 0.83 & 8 \\
\cline { 2 - 7 } & Squirrel\% & -0.4989 & 0.0887 & $<0.0001$ & 1 & 10 \\
\hline \multirow{5}{*}{ Squirrels } & Intercept & -2.542 & 0.5031 & $<0.0001$ & N/A & N/A \\
\cline { 2 - 7 } & Distance & -3.462 & 1.025 & 0.0007 & 1 & 2 \\
\cline { 2 - 7 } & Food & -0.8339 & 0.1603 & $<0.0001$ & 1 & 2 \\
\cline { 2 - 7 } & Food : Guard & 2.008 & 0.326 & $<0.0001$ & 1 & 2 \\
\cline { 2 - 7 } & Garden\% & 0.2667 & 1.091 & 0.8069 & 0.27 & 1 \\
\cline { 2 - 6 } & Guard & 3.280 & 1.040 & 0.0016 & 1 & 2 \\
\cline { 2 - 6 }$\%$ & Rain\% & -0.2929 & 0.1417 & 0.0388 & 1 & 2 \\
\hline
\end{tabular}

631

632 Table 1

633 


\begin{tabular}{|c|c|c|c|c|c|c|}
\hline $\begin{array}{l}\text { Tested } \\
\text { Model }\end{array}$ & Variables & Estimate & $\begin{array}{l}\text { Adjusted } \\
\text { SE }\end{array}$ & $\mathrm{P}$ & \begin{tabular}{|l|} 
Relative \\
Importance
\end{tabular} & $\mathrm{N}$ \\
\hline \multirow{8}{*}{ Blue Tit } & Intercept & 0.1437 & 0.4264 & 0.7361 & N/A & N/A \\
\hline & Distance & 0.2533 & 0.8606 & 0.7685 & 0.15 & 1 \\
\hline & Food & 0.1393 & 0.0638 & 0.0291 & 1 & 4 \\
\hline & Food : Squirrel\% & 0.3306 & 0.1584 & 0.0369 & 1 & 4 \\
\hline & Garden $\%$ & -1.390 & 0.8320 & 0.0949 & 0.71 & 3 \\
\hline & Guard & -0.5986 & 0.9715 & 0.5378 & 0.17 & 1 \\
\hline & Rain\% & -0.1568 & 0.0693 & 0.0237 & 1 & 4 \\
\hline & Squirrel\% & -0.6641 & 0.1082 & $<0.0001$ & 1 & 4 \\
\hline \multirow{8}{*}{ Coal Tit } & Intercept & -6.500 & 1.419 & $<0.0001$ & N/A & N/A \\
\hline & Distance & -1.003 & 1.958 & 0.6083 & 0.1 & 2 \\
\hline & Food & 1.815 & 0.2103 & $<0.0001$ & 1 & 14 \\
\hline & Food : Squirrel\% & 0.9048 & 0.6843 & 0.1861 & 0.43 & 6 \\
\hline & Garden $\%$ & 2.391 & 2.461 & 0.3312 & 0.31 & 5 \\
\hline & Guard & 3.255 & 2.430 & 0.1804 & 0.45 & 6 \\
\hline & Rain\% & -0.1798 & 0.2152 & 0.4034 & 0.22 & 4 \\
\hline & Squirrel\% & -0.9086 & 0.3506 & 0.0096 & 1 & 14 \\
\hline \multirow{10}{*}{ Dunnock } & Intercept & -8.988 & 2.267 & $<0.0001$ & N/A & N/A \\
\hline & Distance & -7.993 & 5.135 & 0.1196 & 0.73 & 2 \\
\hline & Food & 3.156 & 0.4355 & $<0.0001$ & 1 & 3 \\
\hline & Food : Guard & -0.0440 & 0.8551 & 0.9590 & 1 & 3 \\
\hline & Food : Guard : Squirrel\% & -6.214 & 1.917 & 0.0012 & 1 & 3 \\
\hline & Food : Squirrel\% & 0.9480 & 0.9613 & 0.3241 & 1 & 3 \\
\hline & Garden $\%$ & -1.087 & 2.875 & 0.7055 & 0.2 & 1 \\
\hline & Guard & -6.874 & 4.068 & 0.0911 & 1 & 3 \\
\hline & Guard : Squirrel $\%$ & -1.915 & 1.014 & 0.0590 & 1 & 3 \\
\hline & Squirrel\% & 1.587 & 0.5091 & 0.0018 & 1 & 3 \\
\hline \multirow{9}{*}{ Great Tit } & Intercept & -0.3893 & 0.4776 & 0.4150 & N/A & N/A \\
\hline & Distance & 1.175 & 0.9455 & 0.2139 & 0.23 & 1 \\
\hline & Food & 1.806 & 0.0858 & $<0.0001$ & 1 & 5 \\
\hline & Food : Guard & -1.018 & 0.1723 & $<0.0001$ & 1 & 5 \\
\hline & Food : Squirrel\% & -0.1527 & 0.2216 & 0.4907 & 0.14 & 1 \\
\hline & Garden\% & -1.887 & \begin{tabular}{|l|}
1.049 \\
\end{tabular} & 0.0721 & 0.81 & 4 \\
\hline & Guard & 0.0521 & 1.154 & 0.9640 & 1 & 5 \\
\hline & Rain\% & -0.1576 & 0.0843 & 0.0615 & 0.86 & 4 \\
\hline & Squirrel\% & -0.3974 & 0.1327 & 0.0027 & 1 & 5 \\
\hline \multirow{9}{*}{ Nuthatch } & Intercept & -9.982 & 2.022 & $<0.0001$ & N/A & N/A \\
\hline & Distance & 0.4619 & 2.705 & 0.8644 & 0.06 & 1 \\
\hline & Food & 1.820 & 0.5892 & 0.0020 & 1 & 11 \\
\hline & Food : Guard & -0.1693 & 1.548 & 0.9129 & 0.47 & 5 \\
\hline & Food : Guard : Squirrel\% & 9.104 & 6.035 & 0.1314 & 0.16 & 2 \\
\hline & Food : Squirrel\% & -2.569 & 2.912 & 0.3777 & 0.21 & 3 \\
\hline & Garden $\%$ & -2.411 & 2.804 & 0.3898 & 0.21 & 3 \\
\hline & Guard & 0.3488 & 2.658 & 0.8956 & 1 & 11 \\
\hline & Guard : Squirrel\% & -3.895 & 2.155 & 0.0708 & 1 & 11 \\
\hline
\end{tabular}




\begin{tabular}{|l|l|l|l|r|l|l|}
\hline \multirow{5}{*}{} & Rain\% & -0.3605 & 0.3044 & 0.2363 & 0.34 & 4 \\
\cline { 2 - 7 } & Squirrel\% & 0.0047 & 1.068 & 0.9965 & 1 & 11 \\
\hline \multirow{5}{*}{ Robin } & Intercept & -2.038 & 0.4290 & $<0.0001$ & N/A & N/A \\
\cline { 2 - 7 } & Distance & -1.062 & 0.8411 & 0.2067 & 0.4 & 3 \\
\cline { 2 - 7 } & Food & 3.405 & 0.1558 & $<0.0001$ & 1 & 7 \\
\cline { 2 - 7 } & Food : Guard & 2.016 & 0.3018 & $<0.0001$ & 1 & 7 \\
\cline { 2 - 7 } & Garden\% & -0.9463 & 0.9242 & 0.3059 & 0.26 & 2 \\
\cline { 2 - 7 } & Guard & -0.8267 & 0.9157 & 0.3666 & 1 & 7 \\
\cline { 2 - 7 } & Rain\% & 0.0769 & 0.0917 & 0.4016 & 0.22 & 2 \\
\cline { 2 - 8 } & Squirrel\% & -0.3041 & 0.1533 & 0.0474 & 0.91 & 6 \\
\hline
\end{tabular}

Table 2

635 
a)

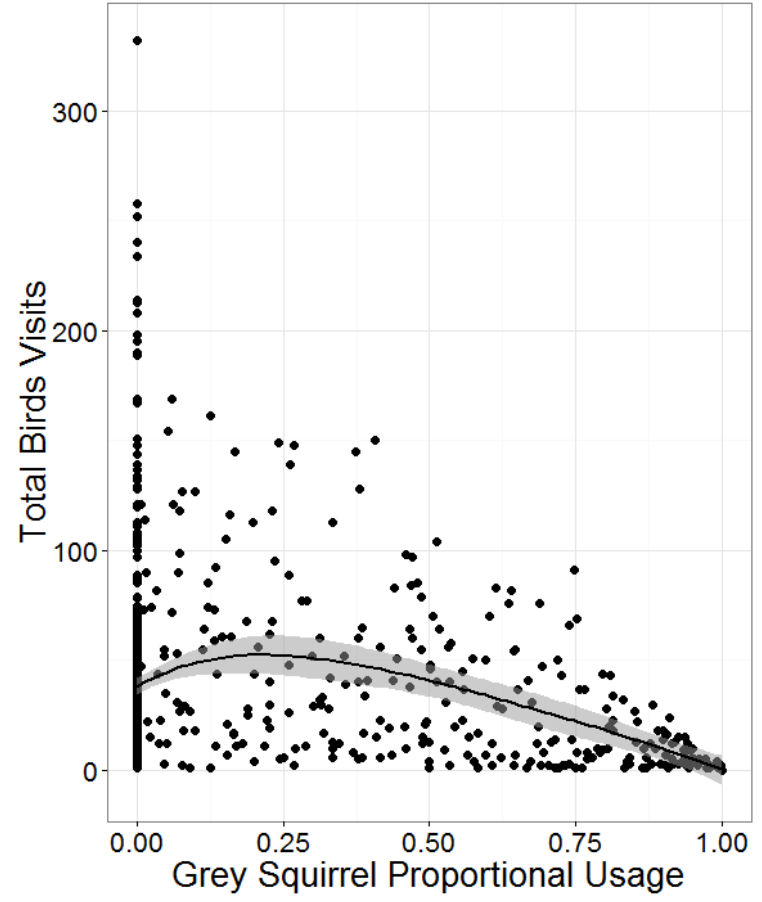

b)

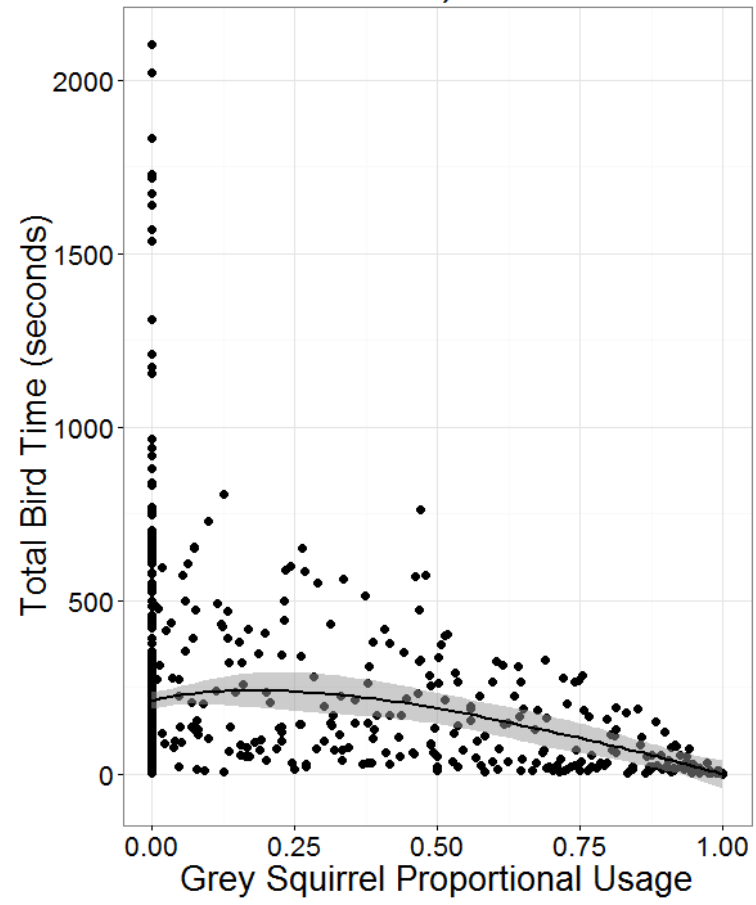

637 Figure 1

638 


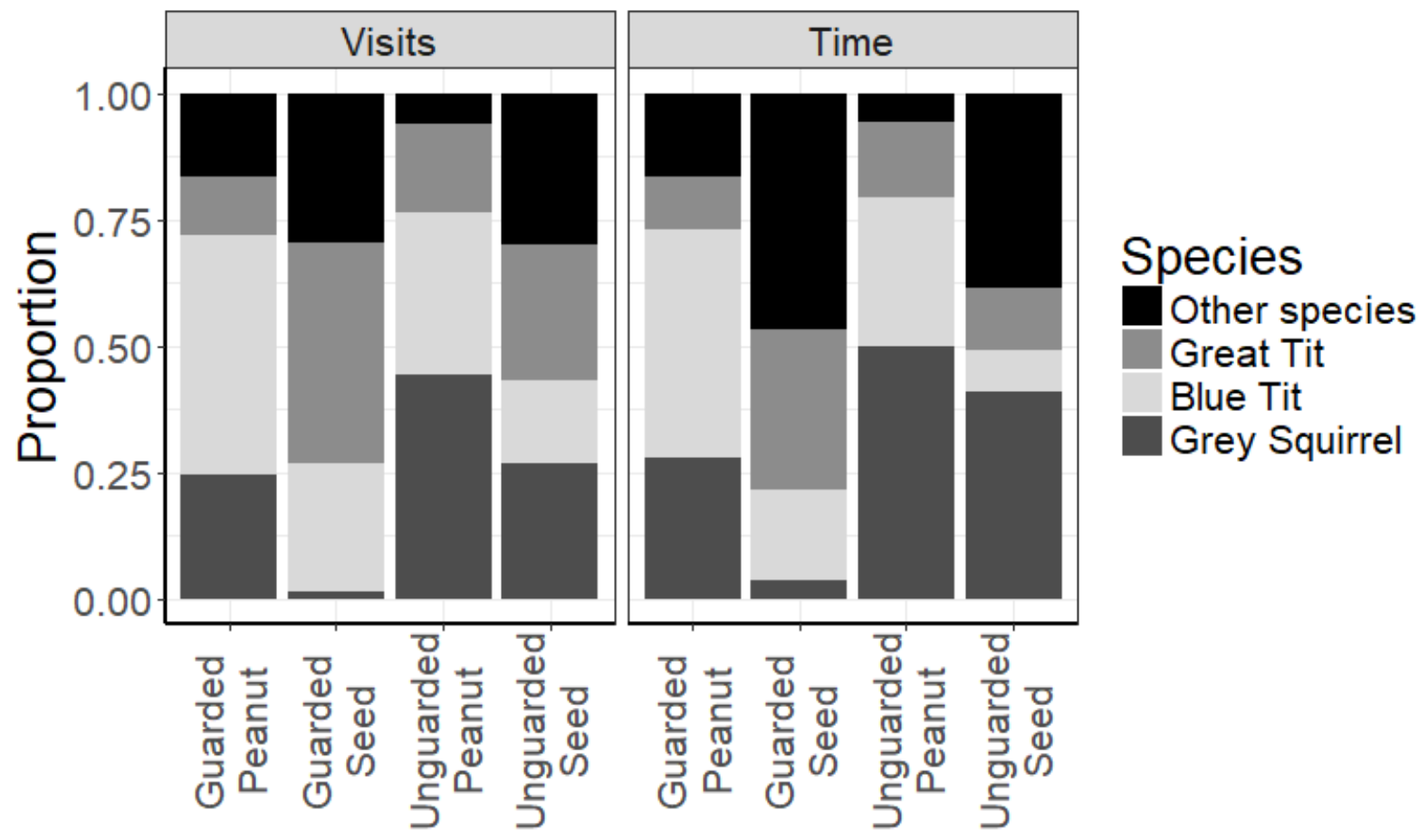




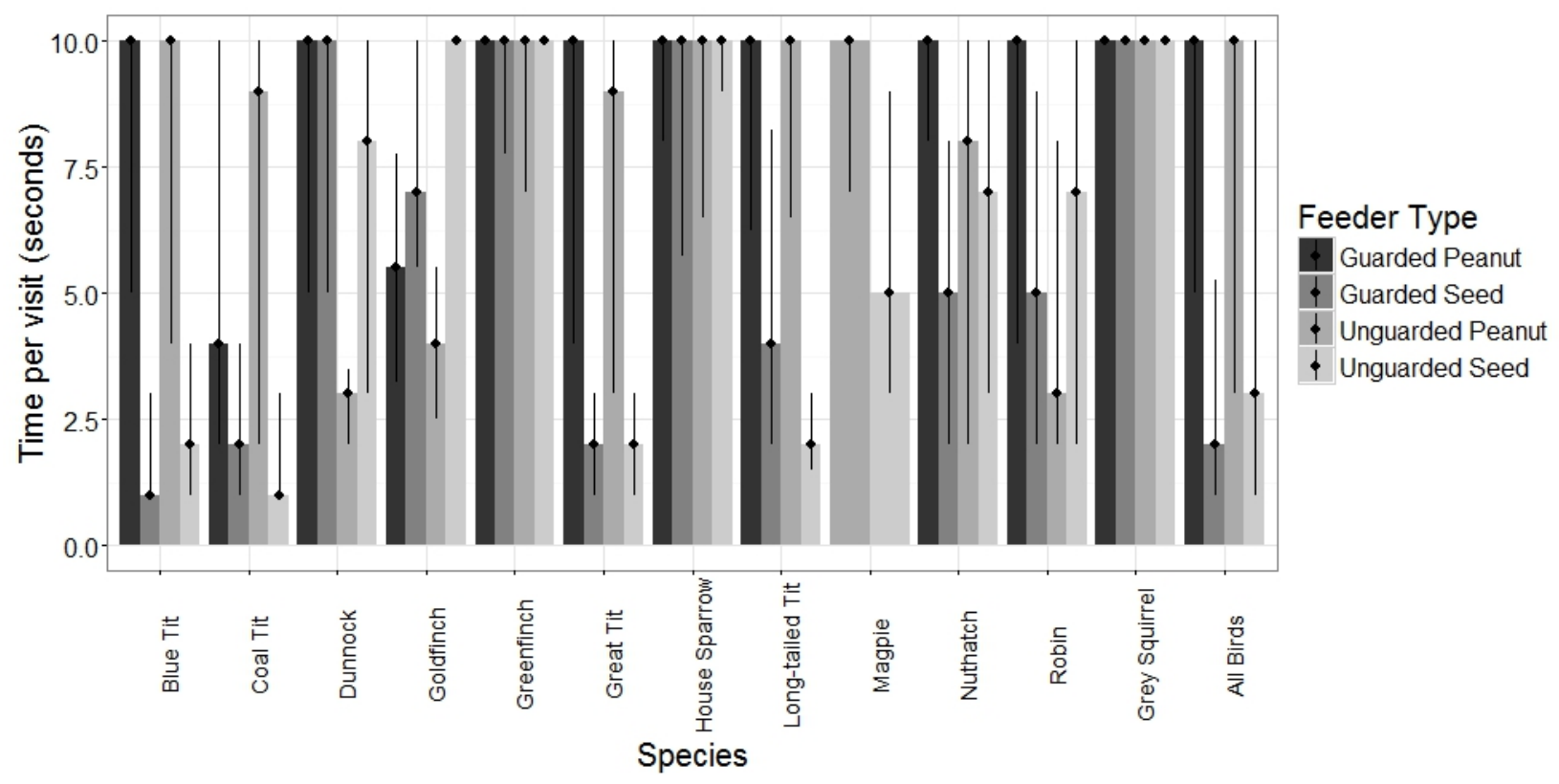

643

Figure 3

645 


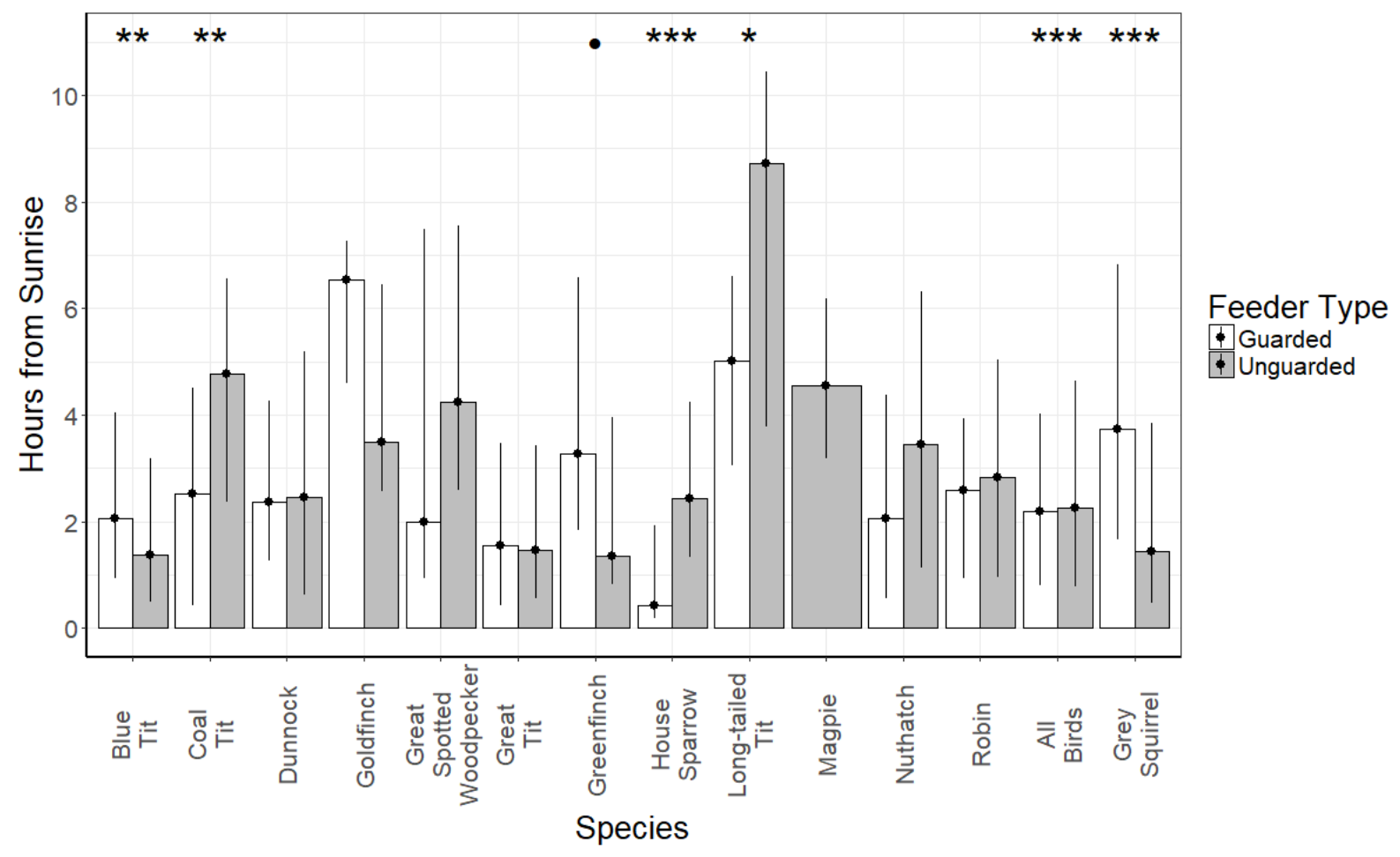

Figure 4 